\title{
The Community Reinforcement Approach: History and New Directions
}

\author{
Robert J. Meyers \\ Michael Villanueva \\ Jane Ellen Smith \\ University of New Mexico \\ Albuquerque, NM
}

\begin{abstract}
This article provides an overview of 2 closely linked treatment approaches for the substance abusing client: The Community Reinforcement Approach (CRA) and Community Reinforcement and Family Training (CRAFT). In 1973, Hunt and Azrin created CRA in an attempt to restructure an individual's "community" so that a sober lifestyle was more rewarding than one dominated by alcohol. One salient CRA premise was that an individual's substance abuse recovery was heavily influenced by his or her social and occupational environment. Sisson and Azrin (1986) later built upon this premise in their work with a new type of client; the loved one of an alcoholic individual who refused to enter treatment. This program was an early version of CRAFT, which is an intervention that works through a nonusing individual to affect the behavior of a substance abuser. This article provides an empirical review of the evolution of these 2 interventions, including their application to illicit drug using clients. It also outlines the clinical procedures that comprise CRA and CRAFT, and considers future research directions.
\end{abstract}

Keywords: [AU: Provide 4 to 6 keywords for indexing]

AU: Provide 4 to 6 keywords for indexing

$\mathrm{T}$ he Community Reinforcement Approach (CRA) is a cognitive-behavioral intervention that was founded on the belief that environmental contingencies play a critical role in encouraging or discouraging substance abuse (Hunt \& Azrin, 1973). Accordingly, CRA utilizes community (i.e., familial, social, recreational, and occupational) reinforcers to support change in an individual's drinking or drug using behaviors. In essence, the goal is to rearrange environmental contingencies such that sober behavior becomes more rewarding than substance abusing behavior. This comprehensive intervention blends operant conditioning with a social systems approach to address multiple problem areas.

In this chapter we outline the history of CRA, beginning with its original use with alcohol patients, and then tracing its eventual application to drug using populations. Additionally, we discuss the development of an outgrowth of CRA designed to work with the loved ones of treatment-refusing substance abusers; namely, Community Reinforcement and Family Training 
(CRAFT). Briefly, three early, well-designed studies demonstrated CRA to be more effective than existing standard treatment for alcohol dependence (Azrin, 1976; Azrin, Sisson, Meyers, \& Godley, 1982; Hunt \& Azrin, 1973). Some of the more recent alcohol studies replicated this success with larger, ethnically diverse samples (Smith, Meyers, \& Delaney, 1998). In the four meta-analytic reviews of treatments for alcoholism conducted over the past 12 years, CRA has consistently placed among the top programs. Depending on the review, it has been ranked from the first to the fifth position out of a group of 30-50 interventions (Finney \& Monahan; 1996; Holder, Longabaugh, Miller, \& Rubonis, 1991; Miller et al., 1995; Miller, Wilbourne, \& Hettema, 2003). In addition to its contributions to the alcohol field, CRA has a more recent history of being used in conjunction with contingency management programs to treat illicit drug abusing populations (e.g., Higgins et al., 1993; Higgins et al., 1995). As noted, CRA also evolved into a format (i.e., CRAFT) that could be used with the concerned significant others (CSOs) of treatment-resistant substance abusers.

CRA programs appear appropriate for a wide range of clients. It has been shown effective with clients having anywhere from mild to severe alcohol problems, and with goals of either reduced drinking or abstinence. Furthermore, CRA has been successful in inpatient, outpatient, and day treatment settings, as well as in both rural and urban environments (Azrin, 1976; Azrin et al., 1982; Hunt \& Azrin, 1973; Smith et al., 1998). Another strength of CRA is its flexibility. The program contains a menu of procedures that can be selected from and tailored to meet a particular client's background and goals. For example, an unemployed client would likely find the job-training component to be of immediate value. A client whose social relationships are rapidly deteriorating due to alcohol abuse might benefit from CRA's communication skills training, or its relationship therapy.

\section{The Community Reinforcement Approach (CRA)}

\section{CRA Treatment Components}

As noted, the entire set of CRA procedures are not necessarily introduced for every client. Exceptions to this are the assessment and treatment planning procedures, which typically are used each time as a starting point. A description of the major procedures that currently are included in most CRA programs is provided below:

1. CRA Functional Analysis: A functional analysis is a method for identifying the framework in which substance abusing behavior occurs. During this task, the client and therapist first jointly map out the antecedents, both external (people, places, times) and internal (thoughts, feelings), that typically are associated with drinking or drug using episodes. The details of the using behavior are outlined next, followed by the positive and negative consequences. Exploring the positive consequences as part of this analysis is critical, so that the factors responsible for reinforcing and maintaining the use are clear. The overall objective is to lay the foundation for a plan that eventually will help the client access psychological and environmental conditions which reinforce sobriety and discourage substance use (Azrin, 1976; Hunt \& Azrin, 1973).

2. Sobriety Sampling: Although abstinence may be the only reasonable goal for many clients, it is common for individuals to become overwhelmed and to terminate treatment if they are immediately given the message that they can never drink/use again for the rest of their lives. Consequently, sobriety sampling was developed as a gentle negotiation process for a time-limited period of sobriety (Azrin et al., 1982). During this period of abstinence, the necessary behavioral skills are taught and the reinforcing aspects of a drug-free lifestyle are emphasized. Sometimes disulfiram is recommended as a tool to facilitate compliance, but if so, only with the use of a trained monitor (Azrin, 1976; Meyers \& Smith, 1995, 
pp. 57-77). At the conclusion of the agreed-upon sober period, the benefits of extending the period are discussed (see Smith \& Meyers, 2001, pp. 41-42).

3. CRA Treatment Plan: Two forms provide the structure for the CRA treatment plan: the Happiness Scale and the Goals of Counseling (see Meyers \& Smith, 1995, pp. 80-101; Smith \& Meyers, 2001). The Happiness Scale is a brief evaluation of satisfaction in 10 areas of a person's life (e.g., job, personal habits, relationships). Based on the results of this assessment, the client and therapist together select areas on which to focus. They then turn to the Goals of Counseling, which lists these same 10 areas and includes questions for each area about goals, strategies for obtaining them, and the projected time frame. The goals for the problem area(s) of interest and the plans for accomplishing them are outlined in brief, positive, specific, and measurable terms.

4. Behavioral Skills Training: In the course of conducting the assessment and developing the treatment plan, areas of behavioral skills deficits typically become apparent that need to be addressed. The three main CRA skills training components are: (a) Problem Solving: This 7-step structured approach to solving problems is a modified version of D'Zurilla and Goldfried's (1971). The objective is to teach clients to break down a problem into manageable pieces, to systematically arrive at a reasonable plan, and to evaluate the outcome. (b) Communication Skills: A simplified approach to assertively discussing difficult issues is taught that minimizes the chance of the listener becoming overly defensive. It involves having the speaker add certain positive components to a conversation (e.g., be brief, be positive, be specific, label your feelings, give an understanding statement, accept partial responsibility, offer to help). (c) Drink/Drug Refusal: This entails role-plays of assertive refusals to use substances. The situations selected for practice are often based on information about triggers from the functional analysis (see Meyers \& Smith, 1995, pp. 102-120).

5. Job Skills: Since a reinforcing job is a significant aspect of one's "community," CRA focuses not only on helping individuals either obtain or keep jobs, but also on determining whether the jobs are satisfying in a variety of ways (e.g., intellectually, financially, socially). The Job Club Counselor's Manual (Azrin \& Besalel, 1980) is relied on heavily for the initial job seeking, whereas the behavioral skills training noted above is used to address job maintenance issues.

6. Social/Recreational Counseling: Therapists often erroneously assume that former substance abusing clients will be able to fill their newly found free time in a healthy and satisfying manner that does not also place them back in an environment with friends who are still using. CRA counselors instead assist clients: in identifying new social activities and encouraging them to sample a few, in addressing the common concerns about socializing while sober, and in dealing with the problem of having a social life that is dominated by individuals who drink or use drugs. Most of the CRA studies also had a Social Club, which was an alcohol-free place to recreate that was available at high-risk times (e.g., weekends). The objective was twofold: to help clients discover that life could be fun without alcohol, and to provide increased opportunities for clients to practice new social skills in a nonthreatening, low-risk atmosphere (Hunt \& Azrin, 1973; Mallams, Godley, Hall, \& Meyers, 1982).

7. Relapse Prevention: This CRA process actually begins with the initial functional analysis, since triggers for episodes are outlined then. In anticipating situations with elevated relapse potential, various behavioral skills are practiced as needed, such as drink refusal and problem solving (Meyers \& Smith, 1995, pp. 180-197).

8. Relationship Counseling: Given the CRA goal of making a client's "community" more reinforcing, it is often worthwhile to include the partners of clients in at least several therapy sessions so that the relationship can be enhanced. Couples sessions usually start with the administration of the Relationship Happiness Scale to each individual, on which they indicate the degree of satisfaction they feel with their partner in each of 10 areas. The Perfect Relationship form is modeled after the Goals of Counseling, and serves as a couples goal-setting plan. The Daily Reminder to Be Nice is a method for gradually reintroducing small pleasant activities back into the relationship (Meyers \& Smith, 1995, pp. 147-179; Smith \& Meyers, 2001, pp. 53-59). 


\section{Early CRA Inpatient Trials}

In 1973, Azrin and colleagues conducted the first in a series of studies comparing CRA to standard 12-step alcohol treatment programs. The original matched control study by Hunt and Azrin (1973) provided the first empirical evidence for CRA's effectiveness. Overall, participants randomly assigned to the CRA condition $(n=8)$ did significantly better than did the standard treatment group participants $(n=8)$ during the first month after hospital discharge. Specifically, CRA participants spent less time drinking and institutionalized, and more time employed and with their families. Importantly, at the 6-month follow-up the CRA group reported drinking only 14\% of the follow-up days while the control group drank $79 \%$ of those days. In a similarly designed second study, Azrin (1976) made several key changes to the original protocol. Most notably, he added a disulfiram (Antabuse) compliance program that involved the assistance of a supportive family member or friend to administer the disulfiram. This "monitor" served as a source of social support for the daily decision to choose sobriety, and was an "early warning notification system" for impending relapse. As part of disulfiram compliance training, participants and their monitors were taught communication skills. The CRA group $(n=9)$ again made greater progress toward recovery than did the standard 12-step treatment group $(n=9)$. For the 6-month follow-up, data were obtained from all 18 participants. CRA participants had significantly better drinking results at this time. They reported using alcohol $2 \%$ of the follow-up days, whereas the control group drank on $55 \%$ of the days. There were significant group differences that favored CRA participants in three other critical areas: employment, time spent with family, and days institutionalized. Although data were unavailable for the 12-step participants at the 2-year follow-up, the 9 CRA group members were abstinent, on average, over $90 \%$ of the days during those 2 years.

\section{CRA With Outpatients}

The third CRA study was conducted with outpatients (Azrin et al., 1982). It primarily examined the effects of the disulfiram compliance component with clients who were randomly assigned to one of three treatment conditions: Traditional Treatment (12-step counseling + a disulfiram prescription; $n=14$ ); Antabuse Assurance (12-step counseling + disulfiram compliance training; $n=15$ ); and CRA + Antabuse Assurance (CRA + disulfiram compliance training; $n=14$ ). Several new CRA procedures were added, including drink-refusal training and sobriety sampling. The two groups receiving the Antabuse Assurance component had the highest abstinence rates overall when compared to the traditional 12-step group at 6 months. A surprising finding was the effect of treatment on married couples: Married participants in the Antabuse Assurance group had significantly higher abstinence rates than did single subjects. The former also performed at the same high level as the couples in the CRA + Antabuse Assurance condition. For the followup during the sixth month, there was an overall significant group difference in terms of days abstinent. The CRA + Antabuse Assurance group was abstinent an average of $97 \%$ of the 30 days, the Antabuse Assurance condition was abstinent $74 \%$ of the days, and traditional treatment averaged $45 \%$ of the days abstinent.

Recently, Miller, Meyers, Tonigan, and Grant (2001) repeated Azrin's 1982 outpatient study, but with methodological changes to increase power $(n=237)$ and further tease out the effects of disulfiram. Also, both disulfiram-eligible and disulfiram-ineligible participants were recruited. The disulfiram-eligible participants were randomly assigned either to one of Azrin's three conditions (traditional treatment, traditional treatment + disulfiram compliance, or CRA + disulfiram compliance), or to a new condition called CRA without disulfiram compliance. This novel condition was created to ascertain whether disulfiram was an essential component of the CRA program. The other two new conditions were for disulfiram-ineligible participants: CRA or traditional treatment. Disulfiram-ineligible participants were those who either had medical contraindications for its use, or who simply refused to take it. 
For the disulfiram-eligible subjects, the intent-to-treat analyses showed that the combined CRA condition (with or without disulfiram compliance) had better outcomes on the drinking variables than the traditional treatment (without disulfiram compliance) at the time of the proximal follow-ups (months 1-6). The largest difference detected was between the percent of days spent drinking for the combined CRA participants (3\%) and for traditional treatment participants (without disulfiram compliance training; 19\%). However, at subsequent follow-ups (months $12 \& 18$ ), the group differences that favored CRA at the earlier follow-ups were lost. Additionally, significant differences were not found between CRA versus traditional treatment groups when participants received disulfiram compliance training. Interestingly, for participants in the new disulfiram-ineligible conditions, the dropout rate for CRA (9\%) was significantly lower than that for traditional treatment (41\%). However, disulfiram-ineligible group comparisons did not reveal any significant group differences in terms of drinking outcomes.

In summary, the results for the proximal follow-ups, which were roughly comparable to Azrin's standard follow-up time, were quite similar to those of the 1982 study. To begin with, CRA participants outperformed traditional group members in terms of drinking outcomes. And when disulfiram compliance training was used to supplement traditional treatment, the findings were similar to those of CRA participants. As a reminder, Azrin discovered this effect of compliance training as well, but only for married participants. Another point to consider is the fact that a much higher percentage of participants in traditional treatment accepted disulfiram (90\%) compared to those in CRA + disulfiram compliance training (56\%). Possibly the results were primarily due to the disulfiram as opposed to the counseling. Further, since disulfiram compliance training includes several CRA components (communication training, segments of relationship therapy), participants in these conditions were receiving an abbreviated dose of CRA that possibly contributed to treatment integrity issues. Another limitation of the study was the unusually low follow-up rate, especially during the earlier phases. For example, the unadjusted follow-up rate at 2 months was only $54 \%$, and at 6 months it was $73 \%$. This increased to $79 \%$ at 24 months. It is unclear whether higher follow-up rates might have affected the outcome substantially, given that there appeared to be only one significant group difference in follow-ups. This occurred at 6 months for the disulfiram-ineligible conditions, when fewer traditional treatment than CRA participants were found.

\section{CRA With Alcohol-Dependent Homeless Individuals}

A natural research extension of CRA's community-oriented intervention was to test its efficacy with the group of people most highly dependent on their ability to navigate and access community resources: the homeless. Recently, Smith and colleagues randomly assigned homeless alcohol-dependent individuals to either a CRA program or a large homeless shelter's standard treatment (Smith et al., 1998). The CRA condition essentially consisted of the usual elements of the CRA package, but was modified slightly to better meet the needs of the often dually diagnosed homeless (e.g., independent living skills training, case management). The shelter's standard alcohol treatment included access to 12-step counselors, on-site Alcoholics Anonymous meetings, and a job program. During this 3 -month program, all participants $(N=106)$ were provided grant-funded housing under the stipulation of abstinence.

Follow-ups were conducted at 2, 4, 6, 9, and 12 months after intake. Follow-up rates for this type of population were noteworthy, ranging from a high of $93 \%$ at 2 months to $76 \%$ at 12 months. Across both conditions there was significant intake through follow-up improvement, with baseline drinking rates of 19 drinks per day decreasing to 3.8 drinks per day at 12 months. As far as between-group differences, the CRA participants' drinking outcomes were significantly better than the standard condition's overall, with the improvement proving robust through the 9-month follow-up. Both treatments showed improvements in housing status, with rates of 
homelessness averaging less than $20 \%$ across the five follow-ups. However, the only significant group difference occurred at 4 months, when CRA participants had higher rates of stable housing. In terms of employment, although there were noteworthy improvements over the 1-year follow-up period, there were no group differences in employment rates at any one follow-up.

\section{Individual CRA Components}

Several components of the CRA program have been individually tested in small studies. As noted, the Social Club was created to provide enjoyable, healthy activities in an alcohol-free environment during high-risk drinking times (e.g., Friday or Saturday nights). A randomized study by Mallams and colleagues (1982) examined the effects of CRA's Social Club in a two-group design. Participants in the Encouragement condition $(n=19)$ received encouragement from their counselors to attend the Social Club, were aided with problem solving to address obstacles that interfered with attendance, and were provided with transportation. The Minimum Awareness participants $(n=16)$ simply were told about the Social Club and given directions for finding it. Data gathered over a 3-month period showed that the Encouragement Group not only frequented the Social Club significantly more often than the Minimum Awareness group, but they drank significantly less alcohol than individuals in the Minimal Awareness condition (0.8 ounces per day vs. 3.3 ounces per day, respectively).

A second individual component of CRA that has been empirically tested is the behavioral couples (relationship) counseling. This "reciprocity counseling" was based on the premise that individuals got married because they thought married life would be more reinforcing than single life. With the therapist's assistance, mutually enjoyable activities were planned as part of the intervention, and individuals were taught that reinforcing acts by a partner needed to be reciprocated. A within-subject study was conducted with 12 couples who were not necessarily experiencing alcohol problems. Significant improvement was shown in marital happiness during the "reciprocity counseling" weeks in contrast to during the "catharsis-type counseling" weeks (Azrin, Naster, \& Jones, 1973).

The CRA component that has received the most research attention is the Job Club. As mentioned, the purpose of the Job Club is to help clients obtain employment that is rewarding in numerous ways. Studies have demonstrated the Job Club's success with a variety of clients, including welfare recipients (Azrin, Philip, Thienes-Hontos, \& Besalel, 1980), prison parolees, and former mental hospital patients (Azrin \& Philip, 1979). Across these samples, individuals randomly assigned to the Job Club obtained significantly higher-paying jobs, and in shorter periods of times than control condition participants.

\section{CRA for the Treatment of Cocaine Abuse}

When treating illicit drug problems, such as cocaine dependence, researchers usually have combined CRA with a contingency management program that offers vouchers for clean urine samples (Higgins et al., 1991, 1993b). The vouchers, which can be traded for material reinforcers, increase in value as the days of continuous abstinence build. Evidence suggests that the use of contingent financial reinforcers early in treatment seems to address the extremely high attrition rates of cocaine-dependent individuals, and competes reasonably with the powerful reinforcing effects of cocaine.

Higgins and colleagues conducted a series of trials comparing a CRA + voucher condition with standard outpatient drug abuse counseling based on the disease model. In their first randomized comparison $(N=38), 58 \%$ of the CRA + voucher participants completed a 24 -week program, in contrast to only $11 \%$ in the control group (Higgins et al., 1993b). As far as continuous weeks of cocaine abstinence, $68 \%$ and $42 \%$ of those in the CRA + vouchers condition achieved 8 and 16 weeks, respectively. For the standard counseling group, the comparable 
percentages were only $11 \%$ and $5 \%$. Importantly, significantly greater cocaine abstinence for the CRA + voucher group versus the standard drug counseling condition was documented via urinalysis at both the 9- and 12-month assessments (Higgins et al., 1995). A randomized study ( $N=$ 40) then compared CRA with and without vouchers in a similar population (Higgins, Budney, Bickel, Hughes, Foerg, \& Badger, 1994). Although urinalyses during the 24-week program showed longer continuous periods of cocaine abstinence for significantly more of the CRA + vouchers participants compared to individuals in the CRA without vouchers condition, there were actually no group differences at the time of the 24 -week assessment. Furthermore, although there were some self-report drug differences noted, there were no longer significant group differences in cocaine abstinence according to urinalyses at the 6-, 9-, and 12-month follow-ups (Higgins et al., 1995). This finding suggests that the CRA program itself is an active treatment component within the CRA + voucher program.

One of the individual CRA components that has been examined in cocaine trials is disulfiram compliance training. As stated earlier, disulfiram compliance initially was introduced to decrease alcohol consumption (Azrin, 1976). Some preliminary findings suggested that it might be beneficial in treating individuals who were dependent on both alcohol and cocaine (Higgins et al., 1993a). Two randomized trials demonstrated that cocaine-dependent individuals who received disulfiram compliance training as part of their treatment protocol had significantly more cocaine and alcohol abstinence when compared with individuals who did not receive it (Carroll et al., 1993; Carroll, Nich, Ball, McCance, \& Rounsaville, 1998). In the more comprehensive study, Carroll and her colleagues randomized 120 outpatients with both alcohol and cocaine dependence diagnoses into one of five treatment groups: cognitive behavioral therapy (CBT) alone; CBT + a disulfiram monitor; 12-step facilitation (TSF) alone; TSF + a disulfiram monitor, or clinical management + a disulfiram monitor. The groups that received the CRAbased disulfiram monitoring system achieved significantly more continuous cocaine and alcohol abstinence than did the nondisulfiram monitoring groups. There were no interactions with the type of treatment. The mechanism responsible for these results is unknown. In part, the belief is that since drinking is often the trigger for cocaine use, one need only target the drinking in order to break the chain of events that leads to cocaine abuse. These studies demonstrate that the disulfiram compliance component of the CRA package has clinical utility for clients diagnosed with combined alcohol and cocaine addictions.

\section{CRA for the Treatment of Opiate Abuse}

Since the outcomes of pharmacotherapies in treating opiate addiction are enhanced when they are combined with effective psychosocial interventions (Onken, Blaine, \& Boren, 1995), it was natural to test whether CRA would qualify as one of them. Thirty-nine opioid dependent individuals who were undergoing a special type of detoxification with buprenorphine were randomly assigned to either a CRA + voucher condition or to standard drug counseling (Bickel, Amass, Giggins, Badger, \& Esch, 1997). Interestingly, half of the vouchers in this program could be earned for opiate-free urines while the remainder could be earned for engaging in treatment-prescribed activities. Significantly more participants in the CRA + vouchers condition completed the 24-week detoxification program (53\%) when compared with those in standard counseling $(20 \%)$, and those in the CRA + voucher group achieved somewhat longer periods of opioid abstinence. These findings offer preliminary evidence for the use of CRA + voucher programs to supplement detoxification protocols in treating opioid-dependent populations.

Abbott and colleagues used CRA without the voucher component to treat methadone-maintained individuals (Abbott, Weller, Delaney, \& Moore, 1998). They randomized 181 participants into three groups: standard counseling, CRA, and CRA + relapse prevention. Given that the relapse prevention was primarily delivered after the 6-month follow-up, the two CRA conditions 
were combined for the analyses on the first 6 months. Significantly more participants assigned to the combined CRA conditions (89\%) achieved at least 3 weeks of continuous abstinence when contrasted with those assigned to standard drug counseling (78\%). At the 6-month follow-up, data for the month prior was contrasted with baseline levels for each variable. The two CRA groups showed significantly greater improvement than the standard counseling condition on the Addiction Severity Index (ASI) drug composite score, which is a calculated estimate of the severity of drug use that is comprised of several individual ASI drug variables. Although the findings are tentative, this offers additional promise for the use of CRA with an opioid-dependent population.

\section{CRA With Adolescent Substance Abusers}

In a recent study, 114 adolescents (76\% male) who were dependent on marijuana (90\%) or alcohol $(57 \%)$ were randomly assigned to one of two types of aftercare conditions once they had remained in a residential treatment center for at least a week. The first condition, Usual Continuing Care (UCC), was a referral to local outpatient providers for continuing care after discharge. A variety of services were available through these programs, including self-help groups, urinalyses, relapse prevention, skills training, and counseling for both the parents and the adolescent. The second condition's treatment was based on CRA, as outlined by Meyers and Smith (1995) and adapted for adolescents by Godley and coworkers (Godley et al., 2001). Adolescent CRA (ACRA) followed the philosophy and procedures of CRA, but it was modified by adding adolescent-relevant components such as a school-related problem area, several standard caregiver sessions, and increased time for trust-building.

At the time of the 3-month assessment, the ACRA group members were outperforming the UCC in terms of both treatment attendance and substance use. Specifically, the ACRA participants had attended significantly more treatment sessions (92\%) than the UCC group (59\%). The ACRA group also had significantly fewer days of drinking and marijuana use than the UCC participants (Godley, Godley, Dennis, Funk, \& Passetti, in press). The promising results from this AU: Update in first empirical test of CRA with adolescents suggest that ACRA merits further study.

press ref?

\section{Community ReInforcement ANd FAmily Training (CRAFT)}

\section{Background}

The newest variant of CRA, CRAFT, was developed in an effort to reach out to the sizeable portion of the substance abusing population (Institute of Medicine, 1990) who absolutely refuse to enter treatment. Rather than dealing with these individuals directly, CRAFT works through concerned significant others (CSOs) by teaching them behavioral procedures for altering their typical methods of interacting with the drinker or drug user. In addition to the goal of getting these resistant identified patients (IPs) to seek treatment, CRAFT also attempts to have them reduce their substance use in the meantime. Finally, it strives to help CSOs take better care of themselves and increase their happiness overall.

An adaptation of CRA for such an intervention seemed reasonable, in part because CRA researchers had already traditionally involved family members in treatment. For instance, CSOs had served as disulfiram monitors, partners in couples therapy, and active players in the quest to establish a healthy, reinforcing community for a substance-abusing individual (Azrin, 1976; Azrin et al., 1982; Hunt \& Azrin, 1973). The notion of working with CSOs to influence a loved one's behavior grew out of the belief that the extensive amount of CSO-IP contact (Stanton \& Heath, 1997) actually made CSOs ideal individuals to directly access powerful IP reinforcers and contingencies. As such, they potentially could play a critical role in engaging a resistant loved one 
into treatment. As intimated above, it was also thought that many CSOs could benefit from assistance in focusing more of their resources on themselves. In fact, statistics showed that the loved ones of individuals who abused alcohol or drugs experienced numerous stressors as a result, including domestic violence, financial problems, marital difficulties, and social embarrassment or isolation (Romijn, Platt, Schippers, \& Schaap, 1992; Velleman et al., 1993). Not surprisingly, these CSOs frequently suffered from depression, anxiety, physical illness, and low self-esteem (Brown, Kokin, Seraganian, \& Shields, 1995; Spear \& Mason, 1991).

Interestingly, CRAFT is nearly a photographic negative of the more commonly available Al-Anon treatment option, which encourages CSOs to accept their powerlessness to influence the alcoholic, to detach, and to focus exclusively on taking care of their own needs (Al-Anon Family Groups, 1984). In contrast, CRAFT empowers and encourages CSOs to get actively involved in the process of helping their IP choose treatment. Importantly, it teaches them how to be "active" in a manner that typically is very different from their past attempts to influence their loved one's substance using behavior.

\section{CRAFT Treatment Components}

A brief description of the main CRAFT procedures are provided below. A reliance upon many of the CRA treatment components should be apparent (see "CRA Treatment Components"). CRAFT CSOs are taught:

1. To determine whether they are appropriate candidates for CRAFT given the risk for increased violence; to recognize the early signs for domestic violence, particularly as new behavioral change techniques are introduced that are intentionally designed to be experienced as negative by the IP; to have a safety plan in place.

2. To use a CRAFT Functional Analysis to outline the triggers of the IP's drinking or drug abuse, as well as the positive and negative consequences of it; to focus on the CSOs' own unintentional role in the maintenance of the IP's using cycle.

3. To communicate more effectively with the IP about a variety of matters.

4. To appropriately and consistently use positive reinforcement for the IP's nonusing prosocial behavior.

5. To withdraw reinforcement at times of IP use; to allow for the natural, negative consequences of the IP's using behavior.

6. To identify their own areas of life dissatisfaction, and develop specific plans for addressing them; to reward themselves more often.

7. To learn the proper method and time for suggesting treatment to the IP; to have a "rapid intake" plan in place to clinically accommodate the IP should he or she agree to treatment.

8. To be prepared to support the IP in therapy; to be patient if the IP continues to refuse treatment or drops out prematurely.

\section{CRAFT Alcohol Trials}

Sisson and Azrin (1986) conducted the first study examining the viability of using communitybased reinforcement procedures with a problem drinker's Concerned Significant Other (CSO). They randomly assigned 12 CSOs to receive either an early version of CRAFT or Al-Anon. In the CRAFT condition, six out of seven resistant alcoholics entered treatment after an average of only 7.2 CSO sessions. In contrast, none of the Al-Anon drinkers sought treatment. Furthermore, the six CRAFT treatment-engaged drinkers each had already reduced their mean consumption by more than $50 \%$ by the time they started the program.

In a large recent trial funded by the National Institute on Alcohol Abuse and Alcoholism (Miller, Meyers, \& Tonigan, 1999), 130 CSOs (91\% female) of treatment-refusing problem 
drinkers were recruited. These CSOs were primarily IP spouses (59\%) or parents (30\%), with the remainder being IP girlfriends/boyfriends, children, or grandparents (11\%). The CSOs were randomly assigned to one of three different engagement approaches: (a) Al-Anon Facilitation Therapy: This one-on-one counseling encouraged attendance at and involvement in Al-Anon meetings, and emphasized getting resistant drinkers to enter formal therapy; (b) Johnson Institute Intervention: This program prepared CSOs for a "surprise" confrontational family meeting with the IP with the objective of getting the drinker to accept treatment; and (c) CRAFT: This intervention taught cognitive-behavioral change skills and new strategies vis-a-vis the CSO for guiding the drinker into treatment. Each therapy was manual-based and consisted of 12 hours of planned contact. To be considered successfully "engaged" an IP had to begin treatment within 6 months from the time of the CSO's first meeting with the therapist.

The CRAFT approach was significantly more effective in engaging resistant problem drinkers into treatment than either of the other two interventions. Specifically, 64\% of CRAFTtrained CSOs successfully engaged their IPs into treatment, compared to $30 \%$ for the Johnson Institute intervention and 13\% for the Al-Anon condition (Miller et al., 1999). Interestingly, 75\% of the CSOs who actually went through with the Johnson Institute intervention's confrontational meeting were able to get their IPs to begin treatment, but only $30 \%$ of the CSOs assigned to that condition completed it. As far as the length of time required by CSOs to get their resistant drinker into treatment, there were no differences when comparing across CRAFT, the Johnson Institute intervention (4.7 CSO sessions each), and Al-Anon (5.7 CSO sessions). Once IPs entered treatment, their median length of stay was 10.5 out of a possible 12 sessions. In terms of CSOs' own functioning, there were no between-group differences. Still, there was significant CSO improvement across conditions from baseline through 6 months for depression, anger, family functioning, and relationship happiness. In addition, the CSOs' enhanced functioning was independent of whether they were able to engage their IP into treatment.

\section{CRAFT With Substance-Dependent Clients}

There have been three studies testing CRAFT with treatment-refusing substance-dependent individuals, with two of them being randomized trials. The uncontrolled pilot project $(N=62)$ demonstrated a 74\% IP engagement rate for CRAFT-trained CSOs (Meyers, Miller, Hill, \& Tonigan, 1999). A study by Kirby and colleagues randomly assigned 32 CSOs either to CRAFT or a 12-step intervention (Kirby et al., 1999). The findings were very similar to the large alcohol trial (Miller et al., 1999) in terms of engagement rates, with $64 \%$ of the CRAFT-instructed CSOs successfully engaging their IPs in treatment, compared to $17 \%$ in the 12 -step condition. Again, improved CSO functioning from baseline through the follow-up (10 weeks) was apparent for both conditions. In a second randomized clinical drug trial (Meyers, Miller, Smith, \& Tonigan, 2002) 90 CSOs ( $88 \%$ female) of illicit drug users were recruited. These CSOs were the IPs' parents $(53 \%)$, romantic partners $(30 \%)$, siblings $(10 \%)$, or the IPs' children or friends $(7 \%)$. The CSOs were randomly assigned to one of three treatments: (a) CRAFT $(n=29)$; (b) CRAFT + aftercare $(n=30)$; which involved weekly group CRAFT sessions for up to an additional 6 months once the CSO had finished the 12 individual sessions; and (c) Al-Anon/Nar-Anon Facilitation Therapy $(n=31)$. All sessions were manual-guided with the option of 12 hours of individual therapy.

It had been hypothesized that the ongoing support of weekly group sessions in the CRAFT + aftercare condition would result in higher engagement rates for that condition in comparison to the others' rates. Although this was the case, it was not a statistically significant difference. Thus, the data for the two CRAFT conditions were combined for subsequent analyses. CSOs in the combined CRAFT conditions were significantly more successful at engaging their IPs into treatment (67\% engaged) than were the CSOs in the Al-Anon/Nar-Anon condition (29\% engaged). 
Once engaged, IPs attended an average of 7.6 therapy sessions out of a possible 12. Although CSO functioning improved from baseline through the 12-month follow-up, the change did not reach significance in this study when the analyses were corrected for multiple tests.

In summary, the research suggests that CRAFT is a highly effective method for engaging treatment-refusing substance abusers into treatment. It has repeatedly outperformed the comparison treatments; namely, 12-step based programs or the Johnson Institute intervention. Its efficacy has been demonstrated with IPs using a variety of legal and illegal substances. Furthermore, CRAFT appears to work well regardless of the type of relationship between the CSOs and the IP, such as whether the CSO is the IP's parent or partner. Importantly, it has been shown equally effective across diverse ethnic groups (Meyers et al., 1999, 2002; Miller et al., 1999).

\section{CONClusions AND Future Directions}

Both CRA and CRAFT have shown efficacy in multiple clinical trials, and yet they remain largely underutilized treatment modalities. Perhaps this is more understandable in the case of CRAFT, since the relevant studies were only published within the last few years, and a treatment manual is still in press (Smith \& Meyers, in press). We can only speculate as to why more clini- AU: Update in cians and programs do not use CRA; a consistently highly ranked cognitive-behavioral alcohol press ref? treatment (e.g., Finney \& Monahan, 1996) that has been in existence for over 30 years and has a treatment manual available (Meyers \& Smith, 1995). As outlined in Miller and Meyers (2001), it probably is due to a combination of factors: limited CRA training opportunities; the belief of some clinicians that since they already are using a few cognitive or behavioral techniques they already are doing CRA; the somewhat "unexciting" basic underlying behavioral theory; and the sometimes unappealing high level of energy that CRA requires of therapists. Additionally, many alcohol programs in the United States are unaccustomed to attributing much importance to the social context in which a substance abuse problem occurs, and consequently CRA's emphasis on social reinforcement contingencies is often not well regarded. Since this is not the norm internationally, it is not surprising then that practitioners in countries such as Sweden, Germany, and England often appear the most enthusiastic about CRA (Miller \& Meyers, 2001). In terms of the limited use of the CRA + voucher program within the illicit drug treatment field, critiques typically report that they are opposed to the idea of "paying" people to be clean and sober, or that the program is too expensive. Regardless of the "real" reason why CRA (and CRAFT) are not utilized more often, a reasonable first step toward a solution is to develop methods of education and dissemination that will entice clinicians to "sample" these treatments. If CRA and CRAFT deliver good treatment outcomes (as the empirical literature suggests they will), one would expect that a therapist would feel reinforced, thereby using them again.

In terms of future CRA and CRAFT research issues to address, there are many options. Within the substance abuse arena, CRA should be tested with less restrictive, more heterogeneous populations that allow for polydrug use and dual diagnoses (e.g., bipolar disorder and substance dependence), since these samples are certainly well-represented in treatment settings (Smith et al., 1998) and too often get excluded from clinical trials. The CRA program should also be modified to better accommodate the unique needs of low-income substance-abusing women, including the problems that arise from their long histories of victimization and the accompanying posttraumatic stress disorder (Brady, Killeen, Saladin, Dansky, \& Becker, 1994). Outside the substance abuse realm, the CRA program could be tested with individuals with other problems, such as eating disorders. Or parts of the CRA package, such as the compliance program that has been used almost exclusively with disulfiram administration, could be applied to psychotropic medication compliance in dually diagnosed individuals. 
Future research directions for CRAFT might entail the recruitment of previously excluded potential participants, such as CSOs who have substance abuse problems themselves, or CSOs embroiled in domestic violence issues with their IPs. Although the latter participant issue is certainly controversial due to concerns about potential danger, the unacceptable alternatives for these CSOs (Caetano, Field, \& Scott, 2003; Sullivan, Basta, Tan, \& Davidson, 1992) are such that it merits investigation. A practical issue that is rather unique to CRAFT within the substance abuse field is the question of where CRAFT-trained clinicians will be "housed." Specifically, most substance abuse centers do not routinely treat nonsubstance-abusing individuals (i.e., CSOs), and many clinicians who do not regularly treat substance-abusing clients mistakenly believe that they must be proficient in the substance-abuse field in order to work with CSOs and deliver CRAFT effectively. Obviously this obstacle must be resolved before reasonable advances in CRAFT dissemination can be attempted. Finally, as with CRA, research may yet demonstrate that CRAFT methods are applicable to the engagement of treatment-refusing individuals with other life problems as well, such as those with clearly paranoid ideation regarding issues such as treatment necessity.

\section{REFERENCES}

Abbott, P. J., Weller, S. B., Delaney, H. D., \& Moore, B. A. (1998). Community reinforcement approach in the treatment of opiate addicts. American Journal of Drug and Alcohol Abuse, 24, 17-30.

Al-Anon Family Groups. (1984). An-Anon faces alcoholism. New York: Author.

Azrin, N. (1976). Improvements in the community-reinforcement approach to alcoholism. Behaviour Research and Therapy, 14, 339-348.

Azrin, N., \& Besalel, V. (1980). Job club counselor's manual. Baltimore, MD: University Press.

Azrin, N., Naster, B. J., \& Jones, R. (1973). Reciprocity counseling: A rapid learning-based procedure for marital counseling. Behaviour Research and Therapy, 11, 365-382.

Azrin, N. H., \& Philip, R. A. (1979). The job club method for the job handicapped: A comparative outcome study. Rehabilitation Counseling Bulletin, 23, 144-155.

Azrin, N. H., Philip, R. A., Thienes-Hontos, P., \& Besalel, V. A. (1980). Comparative evaluation of the job club program with welfare recipients. Journal of Vocational Behavior, 16, 133-145.

Azrin, N., Sisson, R. W., Meyers, R. J., \& Godley, M. (1982). Alcoholism treatment by disulfiram and community reinforcement therapy. Journal of Behavior Therapy and Experimental Psychiatry, 13, 105-112.

Bickel, W. K., Amass, L., Higgins, S. T., Badger, G. J., \& Esch, R. A. (1997). Effects of adding behavioral treatment to opioid detoxification with buprenorphine. Journal of Consulting and Clinical Psychology, 65, 803-810.

Brady, K. T., Killeen, T., Saladin, M. E., Dansky, B., \& Becker, S. (1994). Comorbid substance abuse and posttraumatic stress disorder: Characteristics of women in treatment. The American Journal on Addictions, 3, 160-164.

Brown, T. G., Kokin, M., Seraganian, P., \& Shields, N. (1995). The role of spouses of substance abusers in treatment: Gender differences. Journal of Psychoactive Drugs, 27, 223-229.

Caetano, R., Field, C. A., \& Scott, N. (2003). Association between childhood physical abuse, exposure to parental violence, and alcohol problems in adulthood. Journal of Interpersonal Violence, 18, 240-257.

Carroll, K. M., Nich, C., Ball, S. A., McCance, E., \& Rounsaville, B. J. (1998). Treatment of cocaine and alcohol dependence with psychotherapy and disulfiram. Addiction, 93, 713-728.

Carroll, K. M., Ziedonis, D., O’Malley, S., McCance-Katz, E., Gordon, L., \& Rounsaville, B. (1993). Pharmacologic interventions for alcohol- and cocaine-abusing individuals: A pilot study of disulfiram vs. naltrexone. The American Journal on Addictions, 2, 77-79.

D'Zurilla, T. J., \& Goldfried, M. R. (1971). Problem solving and behavior modification. Journal of Abnormal Psychology, 78, 107-126. 
Finney, J. W., \& Monahan, S. C. (1996). The cost-effectiveness of treatment for alcoholism: A second approximation. Journal of Studies on Alcohol, 57, 229-243.

Godley, M. D., Godley, S. H., Dennis, M. L., Funk, R., \& Passetti, L. L., (2002). Preliminary outcomes from AU: Says "in the assertive continuing care experiment for adolescents discharged from residential treatment. press" in text Journal of Substance Abuse Treatment, 23, 21-32.

Godley, S. H., Meyers, R. J., Smith, J. E., Godley, M.D., Titus, J. M., Karvinen, T., et al. (2001). The adolescent community reinforcement approach for adolescent cannabis users: Cannabis youth treatment (CYT) series, vol. 4 (DHHS Publication No. 01-3489). Rockville, MD: Center for Substance Abuse Treatment, Substance Abuse and Mental Health Services Administration.

Higgins, S. T., Budney, A. J., Bickel, W. K., Badger, G. J., Foerg, F. E., \& Ogden, D. (1995). Outpatient behavioral treatment for cocaine dependence: One-year outcome. Experimental and Clinical Psychopharmacology, 3, 205-212.

Higgins, S. T., Budney, A. J., Bickel, W. K., Foerg, F. E., \& Badger, G. J. (1994). Alcohol dependence and simultaneous cocaine and alcohol use in cocaine-dependent patients. Journal of Addictive Diseases, 13, 177-189.

Higgins, S. T., Budney, A. J., Bickel, W. K., Hughes, J. R., \& Foerg, F. (1993a). Disulfiram therapy in patients abusing cocaine and alcohol. American Journal of Psychiatry, 150, 675-675.

Higgins, S. T., Budney, A. J., Bickel, W. K., Hughes, J. R., Foerg, F., \& Badger, G. (1993b). Achieving cocaine abstinence with a behavioral approach. American Journal of Psychiatry, 150, 763-769.

Higgins, S. T., Delaney, D. D., Budney, A. J., Bickel, W. K., Hughes, J. R., Foerg, F., et al. (1991). A behavioral approach to achieving initial cocaine abstinence. American Journal of Psychiatry, 148, 1218-1224.

Holder, H., Longabaugh, R., Miller, W. R., \& Rubonis, A. V. (1991). The cost effectiveness of treatment for alcoholism: A first approximation. Journal of Studies on Alcohol, 52, 517-540.

Hunt, G. M., \& Azrin, N. H. (1973). A community-reinforcement approach to alcoholism. Behaviour Research and Therapy, 11, 91-104.

Institute of Medicine. (1990). Broadening the base of treatment for alcohol problems. Washington, DC: National Academy Press.

Kirby, K. C., Marlowe, D. B., Festinger, D. S., Garvey, K. A., \& LaMonaca, V. (1999). Community reinforcement training for family and significant others of drug abusers: A unilateral intervention to increase treatment entry of drug users. Drug and Alcohol Dependence, 56, 85-96.

Mallams, J. H., Godley, M. D., Hall, G. M., \& Meyers, R. J. (1982). A social-systems approach to resocializing alcoholics in the community. Journal of Studies on Alcohol, 43, 1115-1123.

Meyers, R. J., Dominguez, T., \& Smith, J. E. (1996). Community reinforcement training with concerned $\overline{\mathrm{AU} \text { : Not in text }}$ others. In V. B. Hasselt \& M. Hersen (Eds.), Sourcebook of psychological treatment manuals for adults. New York: Plenum Press.

Meyers, R. J., \& Miller W. R. (Eds.). (2001). A community reinforcement approach to addiction treatment. Cambridge, England: University Press.

Meyers, R. J., Miller, W. R., Hill, D. E., \& Tonigan, J. S. (1999). Community reinforcement and family training (CRAFT): Engaging unmotivated drug users in treatment. Journal of Substance Abuse, 10, 3, 291-308.

Meyers, R. J., Miller, W.R., \& Smith J. E. (2001). Community reinforcement and family training (CRAFT). AU: Not in text In R. Meyers \& W. Miller (Eds.). A community reinforcement approach to the treatment of addiction. Cambridge, England: University Press.

Meyers, R. J., Miller, W. R., Smith, J. E., \& Tonigan, J. S. (2002). A randomized trial of two methods for engaging treatment-refusing drug users through concerned significant others. Journal of Consulting and Clinical Psychology, 70, 1182-1185.

Meyers, R. J., \& Smith, J. E. (1995). Clinical guide to alcohol treatment: The community reinforcement approach. New York: Guilford Press.

Meyers, R. J., \& Smith, J. E. (1997). Getting off the fence: Procedures to engage treatment-resistant drinkers. AU: Not in text Journal of Substance Abuse Treatment, 14, 467-472. 
Meyers, R. J., Smith, J. E., \& Miller, E. J. (1998). Working through the concerned significant other. In W. R. Miller \& N. Heather (Eds.), Treating addictive behaviors (2nd ed., pp. 149-161). New York: Plenum Press.

Miller, W. R., Brown, J. M., Simpson, T. L., Handmaker, N. S., Bien, T. H., Luckie, L. F., et al. (1995). What works? A methodological analysis of the alcohol treatment outcome literature. In R. K. Hester \& W. R. Miller (Eds.), Handbook of alcoholism treatment approaches: Effective alternatives (2nd ed.). Boston: Allyn and Bacon.

Miller, W. R., \& Meyers, R. J. (2001). Summary and reflections. In R. J. Meyers \& W. R. Miller (Eds.), A community reinforcement approach to the treatment of addiction (pp. 161-170). Cambridge, England: University Press.

Miller, W. R., Meyers, R. J., \& Tonigan, J. S. (1999). Engaging the unmotivated in treatment for alcohol problems: A comparison of three intervention strategies. Journal of Consulting and Clinical Psychology, 67, 688-697.

Miller, W. R., Meyers, R. J., \& Tonigan, J. S. (2001). A comparison of CRA and traditional approaches. In $\overline{A U: \text { Not in text }}$ R. Meyers \& W. Miller (Eds.), A community reinforcement approach to the treatment of addiction. Cambridge, England: University Press.

Miller, W. R., Meyers, R. J., Tonigan, J. S., \& Grant, K. A. (2001). Community reinforcement and traditional approaches: Findings of a controlled trial. In R. Meyers \& W. Miller (Eds.), A community reinforcement approach to the treatment of addiction. Cambridge, England: University Press.

Miller, W. R., Wilbourne, P. L., \& Hettema, J. E. (2003). What works? A summary of alcohol treatment outcome research. In R. K. Hester \& W. R. Miller (Eds.), Handbook of alcoholism treatment approaches: Effective alternatives (3rd ed.). Boston: Allyn and Bacon.

Onken, L. S., Blaine, J. D., \& Boren, J. J. (Eds.). (1995). Integrating behavioral therapies with medications in the treatment of drug dependence. National Institute on Drug Abuse Monograph Series, \#150. NIH publication No. 95-3899. Washington DC: Supt. of Docs., U.S. Government Printing Office.

Romijn, C. M., Platt, J. J., Schippers, G. M., \& Schaap, C. P. (1992). Family therapy for Dutch drug users: The relationship between family functioning and success. International Journal of Addictions, 27, 1-14.

Sisson, R. W., \& Azrin, N. H. (1986). Family-member involvement to initiate and promote treatment of problem drinkers. Journal of Behavior Therapy and Experimental Psychiatry, 17, 15-21.

Smith, J. E., \& Meyers, R. J. (2001). The treatment. In R. J. Meyers \& W. R. Miller (Eds.), A community reinforcement approach to addiction treatment (pp. 28-61). Cambridge, England: University Press.

Smith, J. E., \& Meyers, R. J. (in press). Engaging treatment-refusing individuals with substance use problems: AU: Update in Using the CRAFT program with family and friends. New York: Guilford Press.

Smith, J. E., Meyers, R. J., \& Delaney, H. (1998). The community reinforcement approach with homeless alcohol-dependent individuals. Journal of Consulting and Clinical Psychology, 66, 541-548.

Smith, J. E., Meyers, R. J., \& Miller, W. R. (2001). The community reinforcement approach to the treatment of substance use disorders. The American Journal of Addictions, 10(Suppl.), 51-59.

Smith, J. E., Meyers, R. J., \& Waldorf, V. A. (1999). Covering all bases: Engaging and treating individuals (x 2) with alcohol problems. In J. H. Hannigan, L. P. Spear, N. E. Spear, \& C. R. Goodlett (Eds.), Alcohol and alcoholism: Effects on brain and development (pp. 229-249). Mahwah, NJ: Lawrence Erlbaum.

Spear, S., \& Mason, M. (1991). Impact of chemical dependency on family health status. International Journal of Addictions, 26, 179-187.

Stanton, M. D., \& Heath, A. (1997). Family and marital therapy. In J. H. Lowinson, P. Ruiz, B. Milman, \& J. G. Langrod (Eds.), Substance abuse: A comprehensive textbook (3rd ed., pp. 448-454). Baltimore, MD: Williams \& Wilkins.

Sullivan, C. M., Basta, J., Tan, C., \& Davidson, W. S. (1992). After the crisis: A needs assessment of women leaving a domestic violence shelter. Violence and Victims, 7, 267-275.

Velleman, R., Bennett, G., Miller, T., Orford, J., Rigby, K., \& Tod, A. (1993). The families of problem drug users: A study of 50 close relatives. Addiction, 88, 1281-1289. 